\title{
Direct relationship between breakdown strength and tracking index of composites
}

\author{
Madsen, Søren Find; Henriksen, Mogens; Holbøll, Joachim
}

Published in:

Proceedings of the IEEE International Symposium on Electrical Insulation

Link to article, DOI:

10.1109/ELINSL.2006.1665255

Publication date:

2006

Document Version

Publisher's PDF, also known as Version of record

Link back to DTU Orbit

Citation (APA):

Madsen, S. F., Henriksen, M., \& Holbøll, J. (2006). Direct relationship between breakdown strength and tracking index of composites. In Proceedings of the IEEE International Symposium on Electrical Insulation IEEE. https://doi.org/10.1109/ELINSL.2006.1665255

\section{General rights}

Copyright and moral rights for the publications made accessible in the public portal are retained by the authors and/or other copyright owners and it is a condition of accessing publications that users recognise and abide by the legal requirements associated with these rights.

- Users may download and print one copy of any publication from the public portal for the purpose of private study or research.

- You may not further distribute the material or use it for any profit-making activity or commercial gain

- You may freely distribute the URL identifying the publication in the public portal 


\title{
Direct relationship between breakdown strength and tracking index of composites
}

\author{
S.F. Madsen, J. Holbøll and M. Henriksen \\ Ørsted·DTU, Electric Power Engineering, \\ Elektrovej Building 325, DK-2800 Kgs. Lyngby, Denmark \\ sfm@highvoltage.dk
}

\begin{abstract}
The following paper shows a clear correlation between the measured tracking index and the breakdown field strength for noncoated Glass Fibre Reinforced Polymers (GFRP) with either a polyester or an epoxy based resin. 17 types of specimens have been tested according to IEC Publication 60587 [1]. The breakdown field strength of specimens cut from similar samples is determined by a new method capable of estimating the stressed volume [2]. The results from the two tests are finally compared and incorporated in a single analytical formula. All test specimens are supplied by Danish manufacturers of wind turbine blades and are made under similar conditions and with the same materials and additives as used in the blade manufacture.
\end{abstract}

\section{INTRODUCTION}

Due to increasing demands for more efficient wind power generation and the availability of new manufacturing technologies, the size of wind turbines including the blades is constantly increasing worldwide. The consequence of increasing blade tip height (more than $130 \mathrm{~m}$ above sea level) and the trend of wind farms being placed offshore increases the probability of lightning strikes to wind turbine blades.

When a turbine blade is hit by lightning, the blade is affected depending on the lightning protection installed, the blade geometry and the materials used in manufacturing the blade. Customers and insurance companies are aware of the fact that turbine blades occasionally are struck severely. Despite the considerable cost of repair and outage time, there exists no standard directly aimed at classifying and testing wind turbine blades with respect to lightning.

The efficiency of installed lightning protection on wind turbine blades has previously been estimated according to procedures described in standards designed for lightning protection of aircrafts [3] [4]. These procedures can determine the initial lightning leader attachment point (section 5.1.1 in [3]), as well as the laminates capability of withstanding a swept stroke (section 5.1.2 in [3]).

Increasing the breakdown strength of the blade laminate will increase the probability of passing the tests described in [3]. This also complies with the suggestions stated in previous work which finally may lead to an improved overall efficiency of the lightning protection system.

Measuring the breakdown voltage of composite materials requires large and expensive test setups. On the other hand tracking tests according to [1] are quite simple and inexpensive to perform. The direct aim of this paper is therefore to predict the breakdown field strength of noncoated composite materials based on values for their tracking resistance and simple geometrical parameters.

\section{TEST SETUP, TRACKING}

IEC Publication 60587 describes a test procedure where five similar specimens are tested simultaneously [1]. The results sketched in table I are all obtained by testing according to 'Method 2' in the standard: Stepwise tracking voltage and with the 'End criterion A': Current not exceeding $60 \mathrm{~mA}$. This method implies that the applied voltage is raised $250 \mathrm{~V}$ each hour, while the flow is increased according to a scheme listed in the standard. The result is a code of the form ' $2 \mathrm{~A} 2.5$ ', showing the method 2 , the criteria $\mathrm{A}$ and the highest voltage in $\mathrm{kV}$ withstood by all five specimens 2.5 . In 'Results' this classification is identified as the Tracking Index (TI).

A more detailed explanation of the setup has been given in [5].

\section{TeSt SETUP, BREAKdOWN VOLTAGE}

As a consequence of earlier experiences a new method for evaluating the breakdown strength of composite materials with a plane geometry has been developed [6], [2]. Five main concerns have been incorporated in the final solution:

- The breakdown usually occurs in connection to defects, air filled cavities, in-homogeneities or other impurities. This necessitates a setup where the stressed volume is well known.

- To compare measurements on new materials with samples taken from blades in service, the setup must be flexible enough to allow small differences in geometry.

- Testing specimens with high breakdown strengths usually implies a risk of surface flashover between the electrodes. The probability of surface flashover must be minimized, so that the size and thereby the cost of specimens can be limited.

- To simulate the effect of streamers occurring on the surface of turbine blades, the high voltage electrode must be elevated above the surface.

- In order to compare breakdown field strengths with tracking characteristics of the surface, only streamer formation on this side of the specimen is desired. 
Initial tests and experience led to the following test setup:

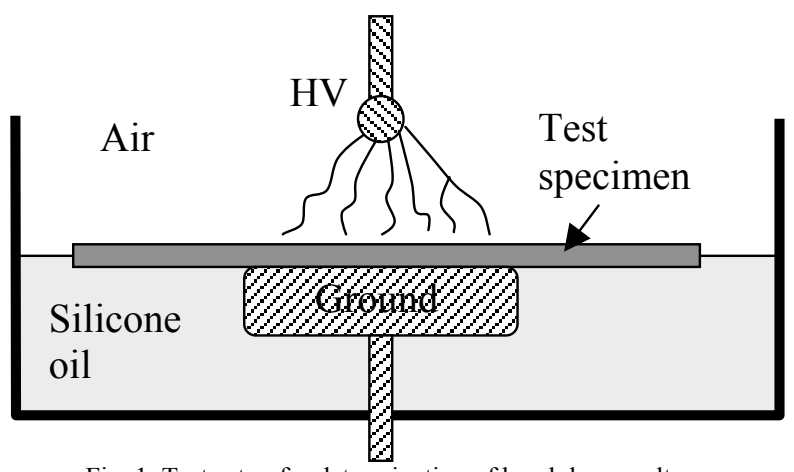

Fig. 1. Test setup for determination of breakdown voltage

An impulse voltage is applied on the upper electrode marked HV which consists of a steel sphere with a diameter $12.5 \mathrm{~mm}$, welded onto a brass rod with a diameter of $4 \mathrm{~mm}$. A cylindrical brass electrode of diameter $70 \mathrm{~mm}$ with rounded edges is used as ground electrode. The connection from the electrode to facility ground is made with a similar brass rod, penetrating the bottom of an acrylic jar.

The test specimen rests on the surface of the ground electrode in an acrylic jar filled with silicone oil. The oil must cover the lower side of the specimen. This decreases the probability of discharges at the lower side of the specimen hereby preventing flashovers between the electrodes. The distance between the HV electrode and the surface of the specimen is $50 \mathrm{~mm}$, allowing streamers to form on the specimen's upper surface.

The test specimens are made of uncoated GFRP and measure $15 \mathrm{~cm} \times 15 \mathrm{~cm}$ with varying thicknesses. They are either cut from samples produced under the same circumstances as real blades, or cut from blades that have been in service.

\section{A. Test procedure, breakdown}

Five specimens of each type were tested for breakdown strength according to Fig. 1, giving a total of 85 specimens.

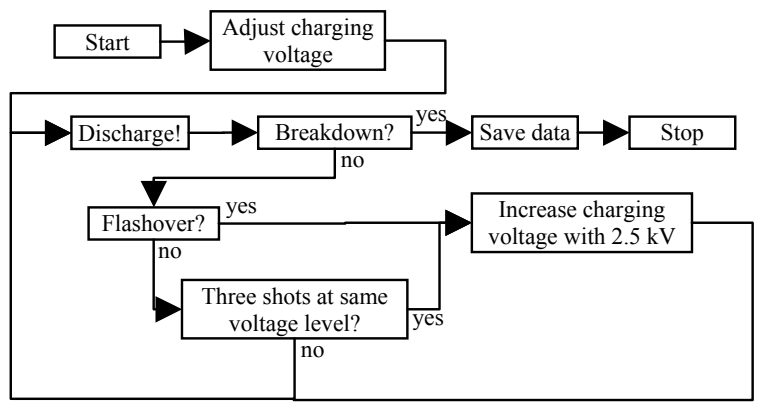

Fig. 2. Flow diagram of test procedure

The voltage applied is a standardized double exponential lightning impulse with a rise time of 1.2 us $+/-30 \%$, and a decay time of 50 us $+/-20 \%$ [8]. A switching type pulse (usually 250/2500 us) would allow more time for streamers to develop [1], but here $1.2 / 50$ us pulses are used, as the objective of this work is to study the breakdown properties of GFRP on relatively small specimens, and not the study of surface discharges.

The test procedure follows the flow diagram in Fig. 2. An initial peak value of the impulse voltage is selected so that the specimen will survive at least three voltage levels. The generator is charged and three subsequent discharges at the selected voltage level are initiated. If neither breakdown nor flashover occurs within these three shots, the charging voltage is increased by $2.5 \mathrm{kV}(8-10 \mathrm{kV}$ peak considering the four stage Marx generator used), and three more discharges are initiated at this new voltage level. If a flashover occurs during one of three shots at the same level, the voltage is raised immediately to the next level. This way of increasing the voltage, depending on whether we have a flashover or not, is continued until a breakdown occurs. The breakdown voltage is defined as the highest voltage achieved at the incident of breakdown.

Three of the five similar specimens are tested with negative polarity, while positive polarity is applied to the two remaining specimens.

\section{RESUlts}

Three results are listed in table I for each type of specimen; the average breakdown field strength at negative polarity,

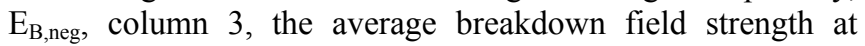
positive polarity, $\mathrm{E}_{\mathrm{B}, \text { pos, }}$, column 4 and the result from the tracking tests, tracking index (TI), column 5.

TABLE I

BREAKDOWN StRENGTH AND TRACKING INDEX FOR VARIOUS NON COATED GFRP MATERIALS

\begin{tabular}{|c|c|c|c|c|}
\hline $\begin{array}{c}\text { Specimen } \\
\text { id. }\end{array}$ & $\begin{array}{c}\text { Thickness } \\
{[\mathrm{mm}]}\end{array}$ & $\begin{array}{c}\mathrm{E}_{\mathrm{B}, \text { neg }} \\
{[\mathrm{kV} / \mathrm{mm}]}\end{array}$ & $\begin{array}{c}\mathrm{E}_{\mathrm{B}, \text { pos }} \\
{[\mathrm{kV} / \mathrm{mm}]}\end{array}$ & $\begin{array}{c}\text { TI (2,A) } \\
{[\mathrm{kV}]}\end{array}$ \\
\hline 1 & 2.04 & -47.5 & 53.5 & 4.50 \\
\hline 2 & 2.04 & -44.2 & 49.7 & 5.00 \\
\hline 3 & 2.25 & -39.5 & 33.6 & 2.00 \\
\hline 4 & 3.06 & -35.9 & 40.7 & 5.25 \\
\hline 5 & 3.06 & -33.7 & 37.8 & 4.50 \\
\hline 6 & 4.08 & -28.5 & 31.8 & 4.25 \\
\hline 7 & 4.08 & -25.5 & 34.4 & 5.25 \\
\hline 8 & 2.04 & -51.7 & $(*)$ & 5.75 \\
\hline 9 & 3.06 & -32.2 & 43.3 & 6.00 \\
\hline 10 & 3.06 & -34.5 & 41.3 & 6.00 \\
\hline 11 & 3.00 & -28.7 & 22.8 & 2.00 \\
\hline 12 & 4.00 & -23.6 & 20.0 & 1.75 \\
\hline 13 & 2.00 & -43.0 & 39.1 & 2.50 \\
\hline 14 & 6.00 & -20.7 & 26.1 & 4.00 \\
\hline 15 & 2.00 & -54.4 & 47.1 & 6.00 \\
\hline 16 & 4.50 & -23.4 & 27.0 & 2.50 \\
\hline 17 & 2.00 & -46.1 & 53.9 & 6.00 \\
\hline
\end{tabular}

$(*)$ The breakdown field strength at positive polarity for specimen no. 8 has unfortunately not been measured.

\section{A. Establishing correlation}

In order to develop an equation that links the results found by tracking tests with results from breakdown tests, some initial considerations must be discussed.

Previous work [6] as well as the results sketched in table I, show that the breakdown field strength tends to decrease with increasing thickness. This is explained by the large amount of 
inhomogeneities present in the laminate, well known as the volume effect.

The roughness of the surface is very important with respect to the tracking results. It has been found that rough surfaces tend to fail at lower voltages than specimens with smooth surfaces [5]. This is especially evident with coated surfaces, but was also seen on the bare laminate. Specimens manufactured with an epoxy based resin also performed better than specimens made with polyester based resin [5]. If these conclusions can be extended to cover the breakdown characteristics, it is assumed that specimens with a higher tracking index will also have a higher breakdown voltage, for similar thicknesses.

With these considerations in mind, different formulas for correlating the tracking index (TI) and the breakdown field strength $\left(\mathrm{E}_{\mathrm{B}-\mathrm{neg}}\right.$ or $\left.\mathrm{E}_{\mathrm{B}-\mathrm{pos}}\right)$ are established. Each formula tends to calculate $E_{B}$ based on TI and the thickness of the specimen. To validate the accuracy, both the relative deviations between the actual and the calculated $\mathrm{E}_{\mathrm{b}}$ as well as the squared deviations are calculated.

To optimize the constants used in the formula, the sum of the squared deviations is minimized (least square method).

\section{B. First approach}

A formula where TI is multiplied with a constant $\left(\mathrm{c}_{1}\right)$ and added to second constant $\left(c_{2}\right)$ divided by the thickness (d) will satisfy the assumption that a higher TI increases $\mathrm{E}_{\mathrm{b}}$, and that $\mathrm{a}$ thicker specimen decreases $\mathrm{E}_{\mathrm{b}}$.

$$
E_{b}=T I \cdot c_{1}+c_{2} / d
$$

By using the least square method, constants for negative and positive polarity are found to be; $c_{1, \text { neg }}=-1.49, c_{2, \text { neg }}=-81.39$ and $c_{1, \text { pos }}=3.98, c_{2, \text { pos }}=58.47$ respectively. The calculated results are shown in table II.

As seen in table II, the sum of the squared deviations is 89.4 for negative polarity and 131.8 for positive polarity. The average deviation is $-0.1 \%$ and $0.7 \%$ respectively, although the highest deviation is $10.2 \%$ for negative polarity and $20.6 \%$ for positive polarity.

TABLE II

Calculated Results Based on the Tracking IndeX and THICKNESS OF SPECIMENS ACCORDING TO (1)

\begin{tabular}{|c|c|c|c|c|c|c|}
\hline Spec. id. & $\begin{array}{c}E_{\text {B-neg }} \\
{[\mathrm{kV} / \mathrm{mm}]}\end{array}$ & $\begin{array}{c}\text { Dev. } \\
\text { squared }\end{array}$ & $\begin{array}{c}\text { Dev. } \\
{[\%]}\end{array}$ & $\begin{array}{c}\mathrm{E}_{\mathrm{B}-\mathrm{pos}} \\
{[\mathrm{kV} / \mathrm{mm}]}\end{array}$ & $\begin{array}{c}\text { Dev. } \\
\text { squared }\end{array}$ & $\begin{array}{c}\text { Dev. } \\
{[\%]}\end{array}$ \\
\hline 1 & -46.6 & 0.8 & -1.9 & 46.6 & 47.7 & -12.9 \\
\hline 2 & -47.3 & 9.7 & 7.0 & 48.6 & 1.2 & -2.2 \\
\hline 3 & $-39,1$ & 0.1 & -0.8 & 34.0 & 0.1 & 1.1 \\
\hline 4 & -34.4 & 2.3 & -4.2 & 40.0 & 0.5 & -1.7 \\
\hline 5 & -33.3 & 0.2 & -1.2 & 37.0 & 0.6 & -2.0 \\
\hline 6 & -26.3 & 4.8 & -7.7 & 31.3 & 0.3 & -1.8 \\
\hline 7 & -27.8 & 5.1 & 8.9 & 35.2 & 0.7 & 2.5 \\
\hline 8 & -48.4 & 10.9 & -6.4 & 51.6 & & \\
\hline 9 & -35.5 & 10.9 & 10.2 & 43.0 & 0.1 & -0.8 \\
\hline 10 & -35.5 & 1.1 & 3.0 & 43.0 & 2.9 & 4.1 \\
\hline 11 & -30.1 & 1.9 & 4.8 & 27.5 & 22.0 & 20.6 \\
\hline 12 & -23.0 & 0.4 & -2.8 & 21.6 & 2.6 & 8.1 \\
\hline 13 & -44.4 & 2.1 & 3.4 & 39.2 & 0.0 & 0.4 \\
\hline 14 & -19.5 & 1.4 & -5.6 & 25.7 & 0.1 & -1.4 \\
\hline 15 & -49.6 & 22.5 & -8.7 & 53.1 & 36.4 & 12.8 \\
\hline 16 & -21.8 & 2.6 & -6.9 & 23.0 & 16.0 & -14.9 \\
\hline 17 & -49.6 & 12.6 & 7.7 & 53.1 & 0.6 & -1.4 \\
\hline \multicolumn{2}{|r|}{ Sum/avg. } & 89.4 & -0.1 & & 131.8 & 0.7 \\
\hline
\end{tabular}

In Fig. 3 the values of the actual measured breakdown field strengths (full and dotted line) and the calculated breakdown field strengths based on the tracking index and the thickness of specimens (squares and triangles) for each of the 17 specimens are plotted. The correlation for both polarities is even more evident in this figure.

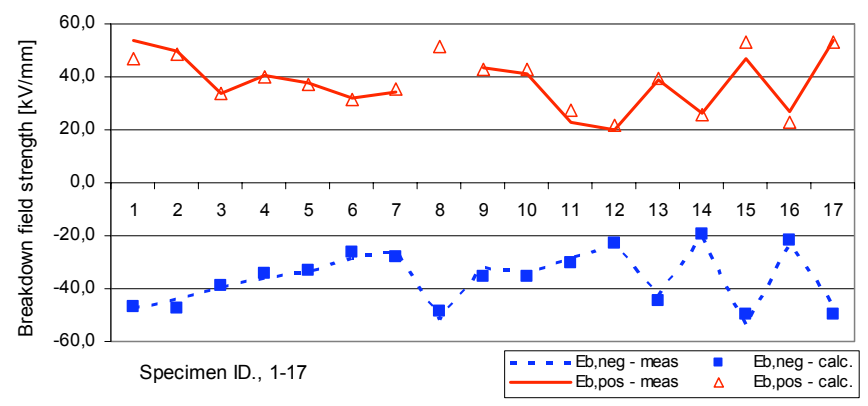

Fig. 3. Comparison of measured breakdown field strengths and breakdown field strengths calculated based on the tracking index and the thickness of specimens for both polarities. The calculated results are obtained by using (1).

\section{Further approaches}

Despite the correlation shown in Fig. 3, several different attempts for a better approximation have also been made.

The same procedure for optimization has been used to find constants for the equations in table III. Values for the squared deviation and the average deviation are given in the four right columns.

TABLE III

FURTHER APPROACHES IN CALCULATING THE Breakdown Field Strengths Based on the Tracking IndeX AND the Thickness of Specimens. The Deviations are to Be Compared with the VALUES IN THE ROW 'SUM/AVG.' IN TABLE II

\begin{tabular}{|c|c|c|c|c|}
\hline Equation & $\begin{array}{c}\text { Dev. } \\
\text { Squared, } \\
\text { neg }\end{array}$ & $\begin{array}{c}\text { Avg dev } \\
\text { neg [\%] }\end{array}$ & $\begin{array}{c}\text { Dev. } \\
\text { Squared, } \\
\text { pos }\end{array}$ & $\begin{array}{c}\text { Avg dev } \\
\text { pos [\%] }\end{array}$ \\
\hline${ }^{(2)} E_{b}=T I^{c_{1}}+c_{2} / d$ & 202.8 & -2.0 & 212.9 & -1.7 \\
\hline${ }^{(3)} E_{b}=T I \cdot c_{1}+c_{2} / d+c_{3}$ & 88.8 & 0.2 & 131.8 & 0.7 \\
\hline${ }^{(4)} E_{b}=T I \cdot c_{1}+c_{2} / d^{c_{3}}$ & 89.2 & 0.0 & 131.7 & 0.5 \\
\hline${ }^{(5)} E_{b}=\frac{T I \cdot c_{1}+c_{2}}{d}$ & 141.5 & -2.9 & 537.9 & -5.1 \\
\hline${ }^{(6)} E_{b}=\frac{T I \cdot c_{1}}{d}$ & 1885.9 & -16.0 & 1551.1 & -17.2 \\
\hline
\end{tabular}

The third constant $c_{3}$ introduced in (3) and (4) gives a minor improvement for both polarities. Values for this constant are given in table IV.

TABLE IV

VALUES OF $\mathrm{C}_{3}$ FOR (3) AND (4)

\begin{tabular}{|c|c|c|}
\hline Equation & $\begin{array}{c}c_{3} \text { pos } \\
\text { polarity }\end{array}$ & $\begin{array}{c}c_{3} \text { neg } \\
\text { polarity }\end{array}$ \\
\hline (3) $E_{b}=T I \cdot c_{1}+c_{2} / d+c_{3}$ & -0.69 & 0.12 \\
\hline (4) $E_{b}=T I \cdot c_{1}+c_{2} / d^{c_{3}}$ & 0.99 & 1.02 \\
\hline
\end{tabular}


Both equations have some similarities with (1) in the first approach. If $c_{3}$ in (3) was set to 0 , the equation would be similar to (1). The same applies to (4) where a value of $c_{3}=1$ gives (1).

Although (3) and (4) show a minor improvement in the accuracy compared to (1), this equation is selected as the most suitable due to its simplicity.

\section{DISCUSSION}

Apparently there is a very good correlation between the result obtained by tracking tests, and the breakdown field strength measured as described earlier. The following equation:

$$
E_{b}=T I \cdot c_{1}+c_{2} / d
$$

describes this relationship where values for $\mathrm{c}_{1}$ and $\mathrm{c}_{2}$ are given in table V.

TABLE V

VALUES OF $\mathrm{C}_{1}$ AND $\mathrm{C}_{2}$ FOR (1)

\begin{tabular}{|c|c|c|}
\hline Equation & Positive polarity & Negative polarity \\
\hline $\mathrm{c}_{1}$ & 3.98 & -1.49 \\
\hline $\mathrm{c}_{2}$ & 58.47 & -81.39 \\
\hline
\end{tabular}

An explanation of this simple correlation could be that the homogeneity or smoothness of a materials surface is an indication of the quality of the bulk material itself. Rough surfaces ability to withstand tracking is restricted by scratches and air cavities on the surface [5]. If these defects are also present inside the specimen, it explains why specimens with a low tracking index tend to have lower breakdown voltages [6]. Another remarkable thing is that breakdown field strength at positive polarity is less affected by the thickness of the specimen than the breakdown field strength at negative polarity (the value of $c_{2}$ in table $\mathrm{V}$ ). This phenomenon might be related to the fact that negative and positive discharges for the specific breakdown test method affect a different percentage of the specimen surface with different composite volumes exposed to the high electric field as a consequence.

To investigate these aspects in detail, UV photographs of discharges in the breakdown test setup were taken.
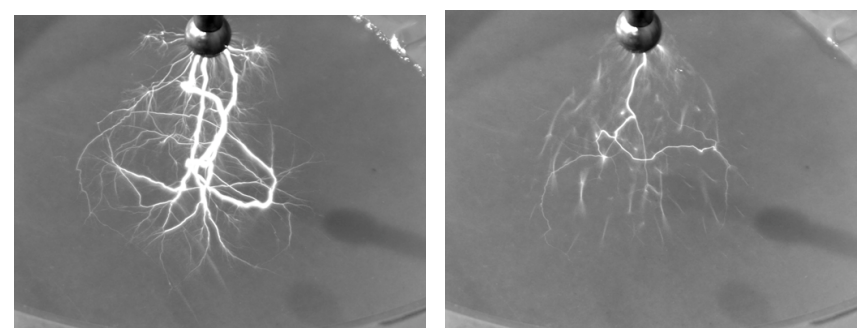

Fig. 4. Left: UV picture of ten positive polarity discharges at app. $100 \mathrm{kV}$ on a $3 \mathrm{~mm}$ plate of phenolic paper (Pertinax), Right: Three negative polarity discharges at app. $130 \mathrm{kV}$ on the same specimen.

The images on Fig. 4 are captured using a setting on the camera that integrates the light intensity of the focus area continuously. This allows the capturing of several discharges within the same image. The idea of such pictures is to identify tendencies that are not covered by a single image. Both images show how the area above the ground electrode is evenly affected for either polarity, but still some fundamental differences between the two polarities are visible.

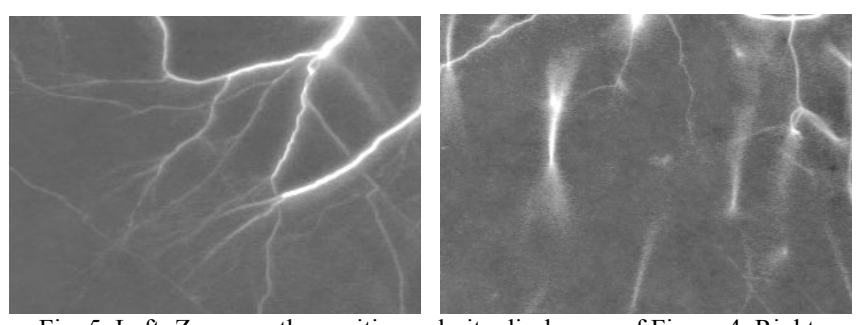

Fig. 5. Left: Zoom on the positive polarity discharges of Figure 4, Right: Zoom on the negative polarity discharges of Figure 4.

Positive polarity discharges appear as filamentary branches connected to the HV electrode extending and splitting up towards the surface of the specimen. By looking closer at the left image of Fig. 5 the surface is met by streamers with very fine filaments, covering the entire area. This corresponds to the theoretical explanations given in [9] and [10]. The negative polarity discharges on the right image on Figure 5 appear as partial bushy discharges occurring randomly in the air above the specimen. Only a few of these discharges have led to a streamer formation from the HV electrode as seen, Fig. 4.

As explained in the literature for mainly large point-plane gaps, the positive discharges do in fact develop as a positive leader extended by filamentary branched streamers [9], [11]. The negative discharges are initiated similarly with a bushy negative corona from the high voltage electrode but develop further in several discrete steps. The initial negative corona is followed by a 'pilot system' somewhere in the electrode gap consisting of both a positive and a negative corona propagating in each direction. At a certain point in time the corona discharges in the pilot system changes into a 'mid gab streamer' appearing as a luminous channel in between the electrodes and developing in both directions [11]. Bushy corona discharges of both polarities are visible in each end of the mid gap streamer, which could be what is seen on the right image of Fig. 5. If time and applied voltage allows for further developing of the negative discharge, the mid gab streamer is met by a negative streamer originating from the high voltage electrode. A few such negative streamers are visible on the right image of Fig. 4.

Apparently there is a major difference in positive and negative polarity discharges and the way they affect the surface of the test specimen. Some indications point in the direction that the surface area and thereby the volume of the test specimen is different for the two polarities. Other explanations could be that the negative discharges stress the surface at smaller spots with increased field enhancement as a consequence. In either case it is necessary to perform further research within this area to develop a full understanding of the differences in the constants $c_{1}$ and $c_{2}$ for negative and positive discharges.

The influence of surface coating has not been incorporated in this paper. 


\section{CONCLUSION}

A simple correlation between the tracking index [1] and the breakdown field strength for non coated composite materials has been found. The relationship enables calculation of the breakdown field strength $\left(\mathrm{E}_{\mathrm{b}}\right)$ by only knowing the tracking index (TI) and the thickness of the specimen (d).

$$
E_{b}=T I \cdot c_{1}+c_{2} / d
$$

The two constants $\mathrm{c}_{1}$ and $\mathrm{c}_{2}$ are found from tests of seventeen different specimens. The test results indicated that a certain polarity dependence existed, such that the thickness of the specimen was more important considering negative polarity discharges than positive polarity discharges. An illustration of the polarity dependence is given using UV photography and common gas discharge physics. The link to the new model needs further research.

The breakdown field strength of laminates used for wind turbine blades may play a significant role in determining the efficiency of commonly used lightning protection. With the equation described in this paper, manufacturers can perform a large number of simple tracking tests prior to the expensive high voltage testing on selected materials.

\section{ACKNOWLEDGEMENTS}

This research project has been financed by means of the Danish PSO-F\&U funding.

\section{REFERENCES}

[1] IEC Publication 587, "Test methods for evaluating resistance to tracking and erosion of electrical insulating materials used under severe ambient conditions", IEC, second edition, 1984.

[2] S.F. Madsen, J. Holboell, M. Henriksen and S. Krog-Pedersen, "Breakdown Tests of Composite Materials, and the Importance of a Volume Effect, NORDIS'2005, Trondheim, Norway, June 13-15.

[3] SAE ARP5416 / Eurocae ED105, "Aircraft Lightning Test Methods, Section 5", Eurocae, draft version V13, 2004.

[4] F.M. Larsen and T. Sorensen, "New Lightning Qualification Test Procedure for Large Wind Turbine Blades”, ICOLSE'2003, Blackpool, England, September $16^{\text {th }}-19^{\text {th }} 2003$

[5] S.F. Madsen, J. Holboell, M. Henriksen and N. Bjaert, "Tracking tests of Glass fibre Reinforced Polymers (GRP) as part of improved lightning protection of wind turbine blades", ICLP'2004, Avignon, France, September $13^{\text {th }}-16^{\text {th }}$.

[6] S.F. Madsen, J. Holboell, M. Henriksen, F.L. Larsen, L.B. Hansen and K. Bertelsen, "Breakdown tests of Glass Fibre Reinforced Polymers (GFRP) as part of Improved Lightning Protection of Wind Turbine Blades", ISEI'2004, Indianapolis, USA, September 19th - 22th.

[7] IEC 243-3, 1993, Methods of test for electric strength of solid insulating materials - Part 3: Additional requirements for impulse tests.

[8] IEC 60-1, 1989, High-voltage test techniques - Part 1: General definitions and test requirements.

[9] E. Kuffel, W.S. Zaengl and J. Kuffel, "High Voltage Engineering Fundamentals", Butterworth-Heinemann, second edition, 2000

[10] M. Akyuz, "Electrical discharges in air and along insulating surfaces", Institute of High Voltage Research, Uppsala University, Sweden, PhD thesis 1999

[11] I. Gallimberti, G. Bacchiega, Anne Bondiou-Clergerie and P. Lalande, "Fundamental processes in long air gap discharges", C.R. Physique 3 (2002) 1335-1359 